TRENDS IN HYDROZOAN BIOLOGY - IV. C.E. MILLS, F. BOERO, A. MIGOTTO and J.M. GILI (eds.)

\title{
A guideline to nematocyst nomenclature and classification, and some notes on the systematic value of nematocysts*
}

\author{
CARINA ÖSTMAN \\ Animal Development and Genetics, Uppsala University, Norbyvägen 18 A, S-752 36 Uppsala, Sweden.
}

\begin{abstract}
SUMMARY: Cnidocyst nomenclature is based on the structure of the tubule and its armature as viewed in the light microscopy (LM). Investigations utilising optically improved LM and scanning electron microscopy have revealed some errors in the interpretation of the fine structure of tubules and armature of nematocysts. Categories of nematocyst have been modified, therefore, to incorporate observations made with new visualising techniques. Isorhizas are defined as nematocysts whose tubule is of uniform or nearly uniform thickness proximal to the midpoint, while b-mastigophores are nematocysts with a rod-shaped encapsulated shaft and a prominent armature on the everted shaft. The category of amastigophores is retained but redefined as p-amastigophores for the V-shaped notch at the base of encapsulated shaft. The trirhopaloids are found to be similar to the birhopaloids. Mesobasic is redefined as an intermediate length of discharged shafts between microand macrobasic. Astomocnidae is redefined as entangling nematocysts and stomocnidae as penetrants.
\end{abstract}

Key words: Cnidaria, nematocyst nomenclature, cnidocysts, isorhizas, mastigophores, amastigophores

\section{INTRODUCTION}

Cnidocysts, or cnidae, are membrane-enclosed cellular organelles or secretions of the golgi apparatus, consisting of a capsule and an eversible tubule (Slautterback and Fawcett, 1959; Watson and Wood, 1988; Arai, 1997). They have been classified traditionally in two major categories, nematocysts and spirocysts (Bedot, 1896; Weill, 1934) to which a third category, the ptychocyst, has been added (Mariscal et al., 1977, see also Watson and Wood, 1988). Cnidarian systematics have considered types of cnidocysts an important systematic character and have defined the cnidome as the census of cnidocyst

\footnotetext{
*Received February 1, 1999. Accepted June 17, 1999.
}

present in a species (Weill, 1934). Cnidomes and information on the size and distribution of cnidocysts are now considered an important part of a species's descriptions (Itô and Inoe, 1962; Kubota, 1976, 1978a,b; Gravier-Bonnet, 1987; Östman, 1983).

Spirocysts and ptychocysts are homogeneous categories, each comprising a single type of cnidocyst. Spirocysts are present only in the Anthozoa, whereas ptychocysts are found exclusively in cerianthids. The capsule wall of spirocysts is thin, and the encapsulated tubule is strongly coiled. The everted tubule lacks spines entirely but secretes a unique adhering, hygroscopic substance (K. W. England, unpublished manuscript). The everted tubules of ptychocysts are woven into the cerianthid's body tube (Mariscal et al., 1977). 
Nematocysts are conspicuously diverse. Weill (1934) divided them into 16 categories. Additional nematocyst types were subsequently identified, climaxing today in over thirty varieties and subvarieties (Carlgren, 1940, 1945; Cutress, 1955; Werner, 1965; Mariscal, 1974; Bouillon et al., 1986; Östman, 1983, 1997; Rifkin, 1996; Östman and Hyman, 1997). Various systems of nomenclature have been devised to cope with this diversity, including Stephenson's (1929), which was also used by den Hartog (1977, 1980), and Schmidt's (1969, 1972, 1974), although, generally, nematocyst classification is based on that of Weill (1934) with modifications made by Carlgren (1940), Cutress (1955), Mariscal (1974), Calder (1977), Rifkin (1996), Östman and Hyman (1997), and the convention on terminology proposed by Watson and Wood (1988).

Weill's nomenclature was based on observations made through the light microscope (LM) primarily of the discharged tubule and its spine pattern. The appearance of the inverted tubule, coiled inside the capsule also contributed distinct diagnostic characteristics (Carlgren, 1940, 1945; Cutress, 1955). The higher resolution achieved by modern LMs and the scanning electron microscope (SEM) have revealed some errors in the interpretation of the fine structures of the nematocysts, in estimates of the tubule diameter and the pattern of spines and thus effects the basic nomenclature of the different categories of nematocysts. For example atrichs are now known to be spined rather than smooth (Cutress, 1955; Calder, 1974; Westfall, 1966a; Heeger et al., 1992; Östman et al., 1995); basitrichs are spined throughout their whole tubules rather than merely spined basally (Cutress, 1955; Westfall, 1966b); tubules of isorhizas taper gradually toward their base rather than remaining isodiametric (Cutress, 1955; Östman and Hyman, 1997); everted microbasic bmastigophores have no shaft rather than a small shaft (Cutress, 1955; Östman, 1983, 1988); amastigophores have a thin tubule beyond the shaft rather than no tubule (Cutress, 1955; England, 1991). Furthermore, isorhizas and anisorhizas, basitrichs and b-mastigophores represent overlapping categories rather than completely separate categories (cf. Cutress, 1955; England, 1991).

The evidence with improved visualisation techniques on structure also alters concepts of nematocyst function, in particular, their function as mini-hypodermic needles. Weill (1934) split the nematocysts into two main groups, the astomocnidae, possessing a tube closed at the tip, and the stomocnidae having an open tip. The stomocnidae generally have coarse spines of different sizes and shapes (Mariscal, 1974; Tardent, 1988; Östman and Hyman, 1997) and were thought to penetrate and inject toxin into prey, predators and competitors. Astomocnidae generally have spineless tubules or tubules armed with only slender, weak spines and were thought to entangle prey (Mariscal, 1974; Östman et al., 1995). Studies by Rifkin (1996) in Chironex fleckeri and by Heeger et al. (1992) in Cyanea capillata, however, have shown that the tips, of at least some fully discharged stomocnide nematocysts are closed, and Rifkin (1996) has shown that toxin can be released from discharged tubules with closed tips. Furthermore, pressure from droplets of capsular matrix flowing down the length of the hollow tubule may cause the end of a closed tubule to rupture. The value of cnidae for systematics, thus, depends on re-evaluating their diagnostic characteristics.

\section{MATERIAL AND METHODS}

Fresh cnidocysts from Hydrozoa, Scyphozoa and Anthozoa have been studied with LM and SEM techniques. Hydroids, family Campanularidae and Tubularidae (see Östman, 1979a,b, 1983, 1988; Östman et al., 1995), scyphopolyps and medusae of Cyanea capillata and Cyanea lamarckii (see Östman, 1997; Östman and Hyman, 1997), sea anemones Gonactinia prolifera, Diadunema cincta, Metridium senile and Sagartiogeton viduatus, and the solitary coral Cariophyllia smithi were from the Gullmar Fjord on the Swedish west coast. The hydroid Halocordyle disticha (see Östman et al., 1991) and the Scyphomedusa Cotylorhiza tuberculata were from the coast of Ischia in the Gulf of Naples, Italy. The siphonophore Apolemia uvaria(?) was collected off the coast of Catalina Island, California, near the Catalina Marine Science Centre. Physalia sp. and the scyphomedusa Cassiopeia xamachana were collected from the coast of Florida near the Whitney Laboratory of the University of Florida. Squash preparations for nematocyst studies were made by the method of Östman (1987) and Östman et al. (1991).

\section{GENERAL CONSIDERATIONS AND RESULTS}

Nematocyst nomenclature based on Weill (1934) distinguishes between nematocysts whose tubules are undifferentiated along their length (isorhizas, 

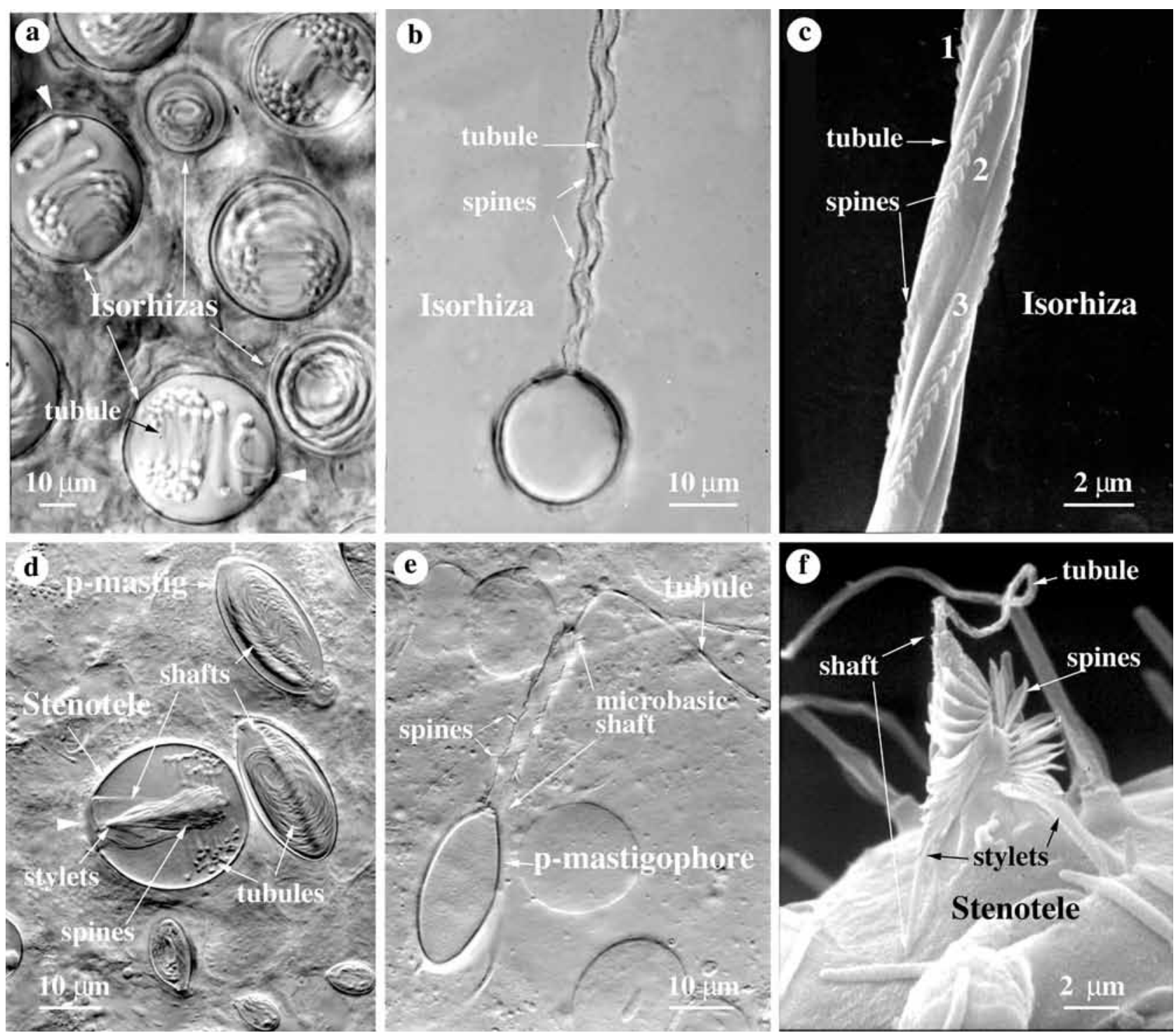

FIG. 1. - a) LM of undischarged O-isorhizas of two size classes of Physalia sp. The tubule is making loosely packed coils perpendicular to the main axis of the capsule. Note the pattern of the first loop of the tubule adhering to the apical tiny, but broad protruding tip (arrowheads). b,c) LM and SEM of isorhizas of Apolemia sp. Note the three rows $(1,2,3)$ of broad-based arrow-shaped spines and the helical structure of the discharged tubule. d) LM of undischarged microbasic p-mastigophores of two size classes of Apolemia sp. and one stenotele. The stylets inside the inverted shaft of the stenotele are pointing towards the aperture of the capsule (arrowhead). Note the pattern of the spines and of the coils of the remaining tubule. The rod-shaped shafts of the p-mastigophores are slightly curved. Their narrow tubules are densely coiled along the main axis of the capsules. e) LM of a discharged microbasic p-mastigophore of Apolemia sp. Note the broad shaft in comparison to the narrow tubule. The spines on the shaft are larger and more prominent than those on the tubule. f) SEM of a discharged stenotele of Halocordyle disticha. Note the stylets and the broad-based spines or lamellae on the upper part of the broad based and apically tapering shaft. The helically twisted pattern is faintly shown on the narrow tubule. 1,2,3, rows of spines; p-amastig, p-amastigophore.

Fig. 1a-c), those whose tubules are broader close to the capsule and taper gradually (anisorhizas), and those whose tubules are divided into a dilated portion or proximal shaft and a thread-like distal tubule (Fig. 1d-f). Tubules may be without spines or armed with three helically-coiled bands of spines (Fig. $1 \mathrm{~b}, \mathrm{c})$, and these may extend throughout the length of the tubule or be restricted to areas. The spines may vary in shape and size from very long to short, from broad-based to slender, from pointed to hook- shaped, from strong to weak, and from prominent to tiny and virtually imperceptible in the LM (Fig. $1 b, c, e, f)$. The initially large penetrating spines of the stenoteles are described by the term stylet (Fig. 1d,f) (see Tardent, 1988). The pattern of spines also varies from close-set to open. These differences in armature may appear along the length of a single nematocyst and between nematocysts.

Large, closely-set spines form a prominent feature of the encapsulated shaft as well as the everted 

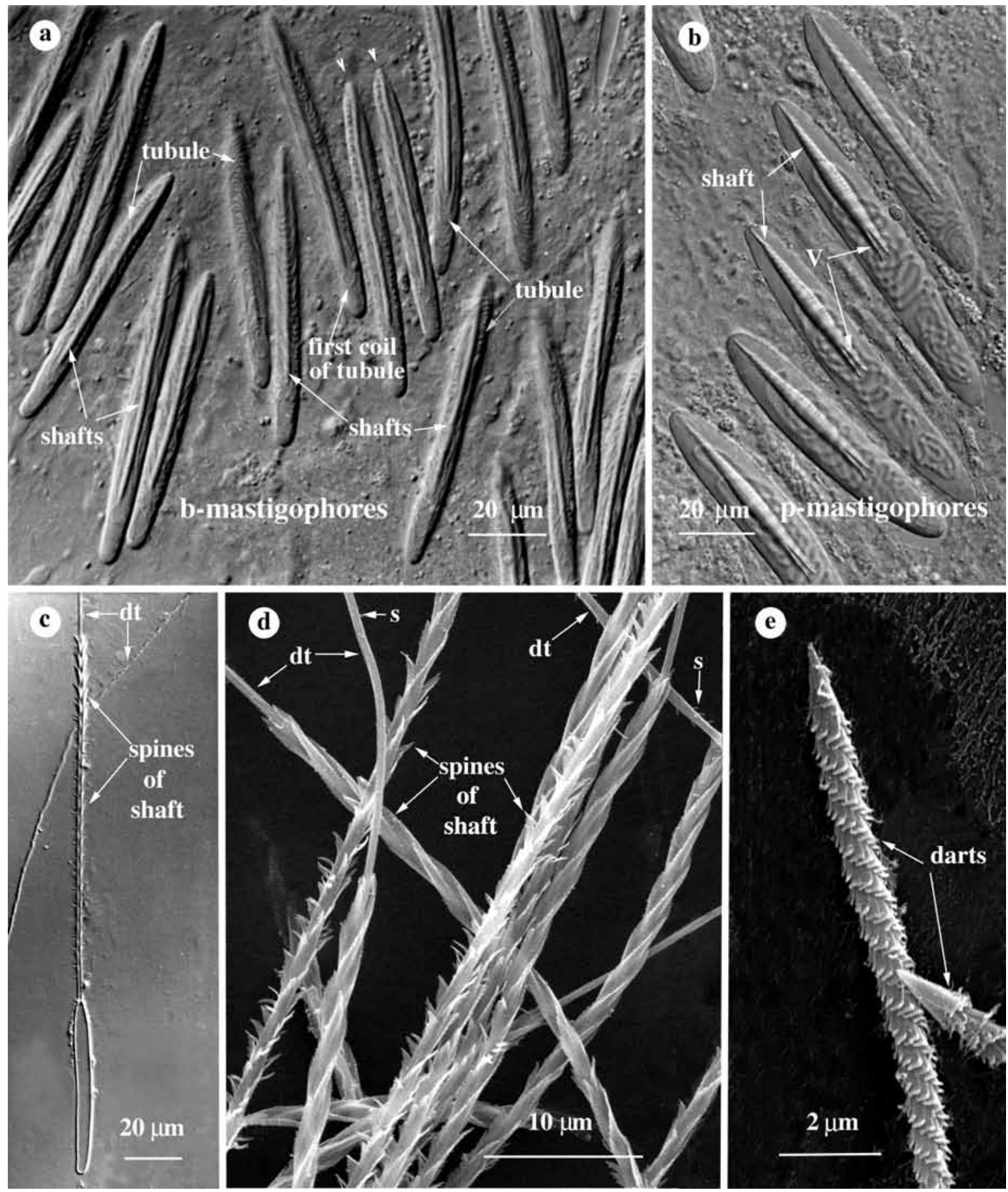

FIG. 2. - LMs and SEMs of b- and p-mastigophores. a) Undischarged mesobasic b-mastigophores of Metridium senile. Note the rod-shaped shafts and the first coil upwards of tubule at end of shaft (arrow). b) Undischarged p-mastigophores of Cariophyllia smithi. Note the V-shaped notch (V) at end of shaft. c) A discharged mesobasic heterotrichous b-mastigophore of Metridium senile. Note the different spinepattern on the shaft. d) Parts of shafts of homotrichous mesobasic b-mastigophores of Metridium senile. Note also the distal tubule (dt) armed with tiny spines (s). e) Parts of darts from Metridium senile. Arrowheads, point at anterior end of capsule; $d t$, distal tubule; $s$, spines on distal tubule; $V$, V-shaped notch at end of shaft

shaft or tubule (Figs 1d, 2a-d). Isorhizas, lacking closely-set, proximal spines (Fig. 1a,b) also lack prominent features in the unfired capsule. The tubule of many nematocysts is simply inverted within the capsule, whereas the broad, inverted shaft of a stenotele or p-mastigophore can be folded back within itself (Figs 1d, 2b; Cutress, 1955; Tardent, 1988).

Carlgren (1940) split nematocysts into two categories based upon the appearance of a prominent 
straight shaft inside undischarged capsules: bmastigophores (Fig. 2a) and the p-mastigophores with a V-shaped notch at base of unfired tubule (Fig. 2b). Cutress (1955) discovered that the shaft of some p-mastigophores had one or more darts and classified these nematocysts as qmastigophores. Hand (1961), Werner (1965) and Mariscal (1974) did not accept Cutress's proposal. They regarded darts as artefacts produced by the cohesion of spines. Schmidt (1974), however, also identified darts, and some structures, interpreted as arrows or darts, were in the present work, identified in SEM preparations of Metridium senile (Fig. 2e). The term mesobasic was coined by England (1991) for microbasic b-mastigophores with a proximal, tightly folded shaft.

\section{Nematocyst nomenclature}

Traditionally, spines and spine patterns were described as follows:

$\begin{array}{ll}\text { atrichous } & \text { without spines } \\ \text { basitrichous } & \text { spines at base of tubule } \\ \text { heterotrichous } & \text { two or more kinds of spines } \\ \text { holotrichous } & \text { tubule spined throughout } \\ \text { homotrichous } & \text { all same kind of spines } \\ \text { spines } & \text { the armature decorating the } \\ & \text { surface of an everted tubule of } \\ & \text { a nematocyst }\end{array}$

stylets initially penetrating large spines

Tubules in the various types of nematocyst were described as follows:

anisorhizas tubule tapers gradually toward distal end

astomocnidae closed tubule (lacks opening at tip)

b-mastigophores lacks V-shaped notch at base of unfired shaft (Fig. 2a)

birhopaloids shaft with a distal and a proximal

(type I)

euryteles

haplonemes

heteronemes

isorhizas

macrobasic

mastigophores p-mastigophores V-shaped notch at base of unfired shaft (Fig. 2b)

pseudostenoteles shaft with short unarmed base separated by a constriction from the armed part of shaft much longer and armed with rows of short spines. Two to four big spines are present at the level of constriction. Other big spines may be present along the row of short spines (Bouillon et al., 1986)

q-mastigophores shaft bears one or more darts (Fig. 2e). The dart is considered to be an unattached structure neatly fitting over the end of the invaginated shaft (Cutress, 1955)

rhabdoids cylindrical shaft, often isodiametric (Figs 1d,e, 2a)

rhopaloids diameter of shaft changes (Figs 1d,f, 3a-f) shaft enlarged basal portion of tubule

trirhopaloids discharged shaft dilated at more than 2 points along length; largest (=middle) swelling bearing spines (Rifkin, 1996)

shaft enlarged basal portion of tubule stenoteles discharged shaft dilated at base, three spines (stylets) especially strongly developed at level of constriction between unarmed basal part and distal spinous portion (Fig. 1d,f)

stomocnidae tubule with opening at tip

The following definitions are new or altered: amastigophores $=p$-amastigophores having a Vshaped notch at base of unfired shaft (Fig. 4c)

birhopaloids (new)the two dilations on shaft close (type II) together (Fig. 3e, similar to the trirhopaloids of Rifkin (1996))

b-mastigophores no V-shaped notch at base of unfired, narrow shaft; discharged shaft or proximal tubule approxi mately the same diameter as remaining tubule, proximal tubule with prominent armature (Fig. 2a,c,d)

isorhizas tubule of uniform or nearly uniform thickness proximal to midpoint of tubule (Fig. 1b) 
mesobasic medium-sized shaft or prominent proximal armature, more than one and a half times but less than for times the capsule length (Fig. 4a,b)

shaft or prominent proximal armature less than one and a half times the capsule length (Figs.1e, 4a,b)
Isorhizas, anisorhizas and basitrichs. No rodshaped shaft visible inside unfired capsule

The tubules of the isorhizas and anisorhizas are simply inverted without portions folded back upon themselves; no shaft (enlargement of the proximal tubule) is visible inside undischarged capsules. Inverted as well as everted tubules of isorhizas are isodiametric or nearly so (Fig 1a,b) in contrast to the
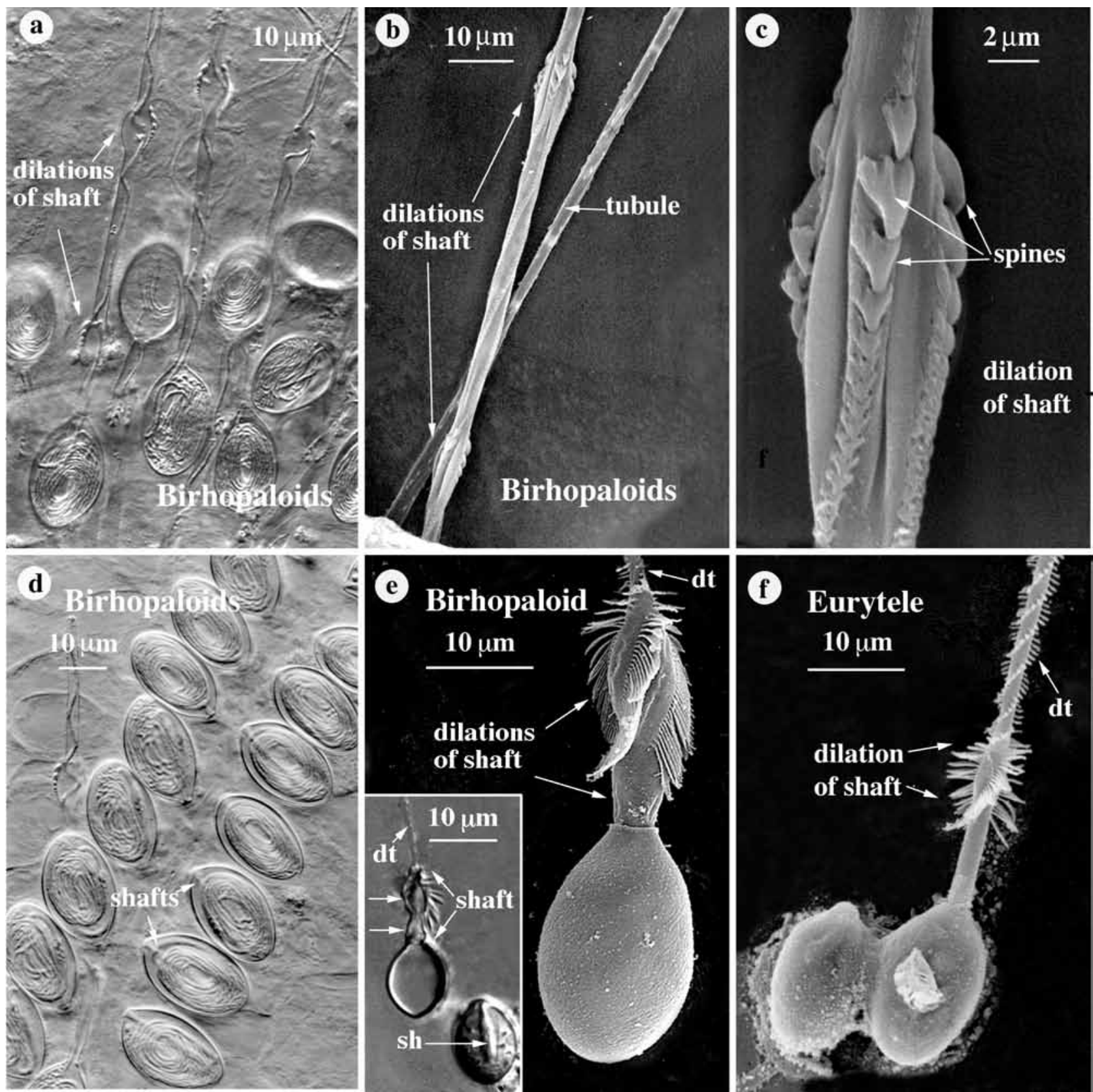

FIG. 3. - a-d) LMs and SEMs of birhopaloids type I of Apolemia sp. a,b) Note the distance between the two dilations or swellings on the shaft. Rows of spines are shown on the dilations and along the shaft. c) The distal dilation showing tree rows of broad-based arrow-shaped spines. d) Undischarged birhopaloid type I showing the inverted shaft and the densely coiled narrow tubule. e) SEM of discharged birhopaloid type II from Cyanea capillata. The two swellings of the shaft are close together. Only the large distal dilation is armed with spines. Insert: LM of discharged and undischarged birhopaloids type II from Cassiopeia xamachana. f) SEM of a eurytele from Cyanea capillata showing the distal dilation of shaft armed with long spines. Note the small spines on the distal tubule (dt). $d t$, distal tubule; sh, shaft. 

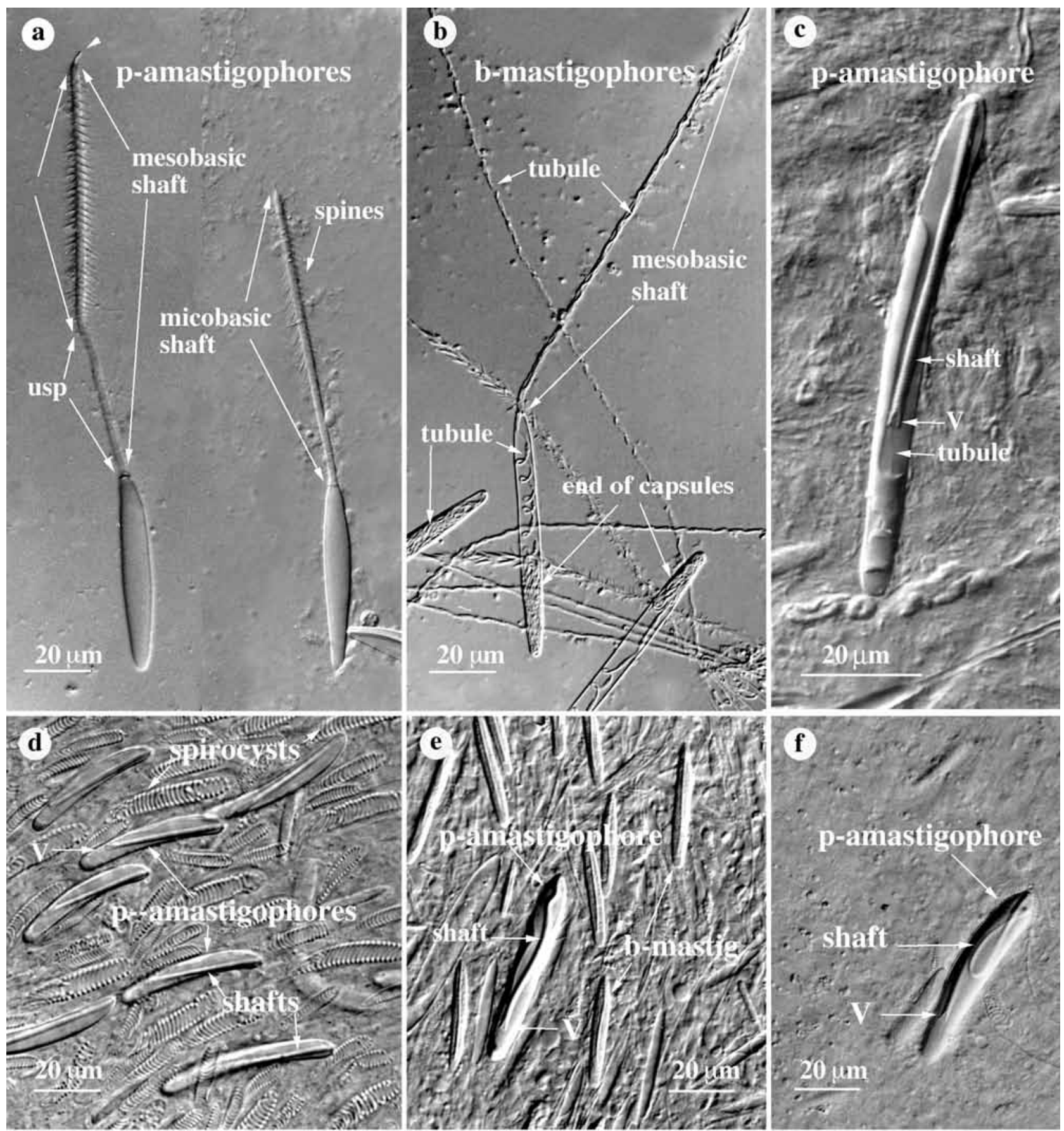

FIG. 4. - LMs of p-amastigophores, b-mastigophores and spirocysts. a) Discharged mesobasic- and microbasic p-amastigophores from Sagartiogeton viduatus. Note the tiny tubule (arrowhead) at end of the mesobasic shaft. b) partly discharged mesobasic b-mastigophores from Metridium senile. Note the coiled tubule inside shaft and capsules. c) An undischarged p-amastigophore from Metridium senile. Note the hardly visible narrow tubule emerging from the V-shaped notch at end of shaft. d) Spirocysts and p-amastigophores from Gonactinia prolifera. Note the position of the shaft. e) b-mastigophores and one p-amastigophore from Sagartiogeton viduatus. Note the undulating shaft of the p-amastigophore. f) An undischarged p-amastigophore from Diadunema cincta. Note the coiled shaft. Arrowhead, point at the tiny tubule at end of shaft; $V, \mathrm{~V}$-shaped notch at end of shaft.

tapering tubules of anisorhizas. In some hydrozoan isorhizas, the loops of the tubule are longitudinally coiled along the capsule axis (Östman, 1983, 1999). In most isorhizas, the inverted tubule begins to form coils close to the aperture, and coils loop back perpendicularly from wall to wall (Fig. 1a). The first coil to be discharged is the one closest to the aperture, and the last one is that at the end of the capsule. This pattern of discharge has been found in scyphozoan isorhizas (Östman and Hyman, 1997), siphonophoran (Fig. 1a), in other hydrozoan isorhizas (Östman et al., 1991) and in actiniarian 
isorhizas. The same pattern has been reported for actiniarian basitrichs (Cutress, 1955).

The inverted tubule of basitrichs with coarse armature close to the capsule can appear shaft-like but is coiled (Cutress, 1955) and not rod-like as in the b-mastigophores (Fig. 2a). Basitrichs thus resemble isorhizas (Cutress, 1955; Östman, 1982) or anisorhizas when their tubules are thick basally.

\section{Nematocysts with shafts visible in the unfired capsule}

The shaft is recognised by its large diameter compared with that of the remaining inverted tubule (Figs 1d, 2a,b, 3c-f). Large, closely-set spines are generally present on shafts, whereas spines are smaller and loosely-set on the distal tubule. The inverted shaft is twisted. Some shafts or parts of shafts are twisted more tightly proximally than distally (Fig. 5a). Other shafts are tightly twisted both proximally and distally (England, 1991). The lengths of shafts vary. Shafts shorter than their capsules generally form a straight axial rod in the centre of the capsule (Figs 2a,b, 4c), while some may follow the curvature of the capsule (Fig. 1d) and others run obliquely across the posterior of the capsule (Fig. 4d). Shafts longer than the capsule may be undulating or coiled (Fig. 4e,f). The diameter of the shaft may vary throughout its length.

\section{Microbasic, mesobasic and macrobasic shafts}

The terms microbasic and macrobasic refer to the length of the discharged shafts. Weill (1934) identified microbasic as nematocysts whose discharged shafts were less than three times the capsule length. Macrobasic nematocysts had discharged shafts longer than four times the capsule length. Rodshaped shafts, similarly tightly twisted throughout and isodiametric, generally bear spines of the same size (i.e., they are homotrichous, Fig. 2d).

Shafts longer than the capsule are accommodated to the confined space by proximal undulations or coils, which are more tightly twisted than in the remaining part of the shaft (Fig. 4e,f, 5a). Schmidt (1969) interpreted the proximal part of the shaft as highly folded. The spines inside this portion are generally smaller and not as closely-set as those of the remaining part of the shaft (i.e., the nematocysts are heterotrichous, Fig. 5a,b,d). Since encapsulated shafts with small and loosely-set spines can be more tightly twisted compared to shafts with large closely-set spines (Fig. 5a-e), when discharged, these folded or twisted shafts are generally longer than less twisted and nonconvoluted shafts. England (1991) introduced the term 'mesobasic' for microbasic nematocysts whose shafts were more tightly folded proximally than on the remaining tubule. Thus only nematocysts with homogeneously twisted shafts were assigned to the category of microbasic by England (1991).

'Mesobasic' would seem more appropriately defined in terms of the shaft's length, rather than its degree of folding, since it is intermediate between micro- and macrobasic. All inverted rod-shaped shafts are more or less tightly twisted and when discharged they are slightly longer than the capsule (Fig. 5a). Encapsulated shafts with a distinct tightly twister, slightly undulating or coiled portion are often longer at discharge than one and a half times the capsule length. Thus, shafts longer than one and a half time the capsule length, but shorter than four times the capsule length, are here designated mesobasic (Fig. 4a).

Microbasic and mesobasic b-mastigophores. Simple inverted shafts in unfired capsules.

By definition (Carlgren, 1940; Cutress, 1955; Mariscal, 1974) microbasic b-mastigophores have a proximal, cylindrical enlargement of the tubule called the shaft. The shafts are less than three times the length of the capsule and gradually taper into the narrower distal tubule (or thread).

The b-mastigophores are recognised by the pattern of their inverted tubule. In unfired capsules, the tubule is simply inverted, forming a narrow, distinct rod-shaped shaft (Fig. 2a). In actiniarian bmastigophores, the inverted tubule coils around the shaft against the capsule wall (Figs. 2a, 6a). The first coils to leave the discharging capsule are those closest to the aperture, and the last coils to evert are those at the posterior end of the capsule. Thus, immediately at the distal end of the unfired shaft the tubule coils back toward the capsule aperture. A similar situation may prevail in the elongated actinarian bmastigophores (Fig. 2a). Studies of broken capsules of Metridium senile under SEM have revealed one loop of the tubule which may coil upward toward the aperture of the capsule (Fig. 6a,c). The remaining tubule forms regular coils from wall to wall around the shaft (Figs. 4b, 6a,c), although some irregular coils are found in the end of the capsule posterior to the base of the shaft (Fig. 6b). 

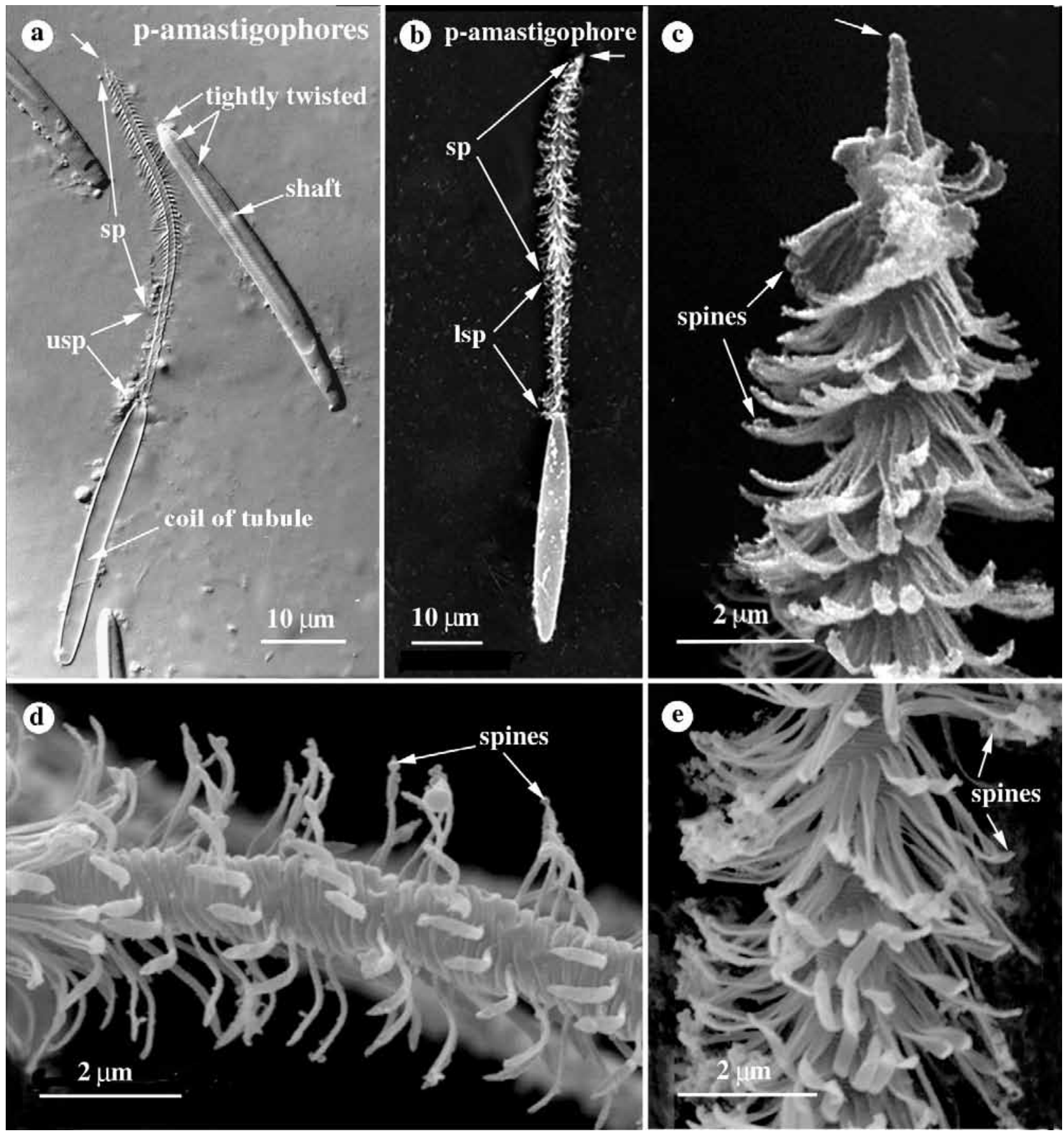

FIG. 5. - LM and SEMs of microbasic p-amastigophores. a) Discharged and undischarged p-amastigophores of Metridium senile. Note the undischarged twisted shaft. The more tightly twisted part of shaft (between arrows) corresponds to the unspined or loosely spined region (usp) of the discharged shaft. The remaining loosely twisted part of shaft corresponds to the heavily spined region (sp). Note coil of tubule inside dischargedcapsule. b) Discharged microbasic p-amastigophores of Sagartiogeton viduatus. Note the heavily spined part of shaft (sp) compared with the loosely spined part (lsp). c) Distal shaft with tip and large closely-set spines. No opening of tubule is seen at the tip. d) Part of shaft showing long loosely-set spines from the lsp-region in fig. b. Note the tight foldings on the shaft corresponding to the posterior more tightly folded part of the inverted shaft (between arrows in fig. a). e) Middle part of shaft showing large closely-set spines (from the sp-region in fig. b). Arrows point at tip of shaft; $s p$, spined region of shaft; $l s p$, region of shaft with loosely-set spines; $u s p$, unspined or loosely-spined region of shaft.

The spines on the shaft are of considerably different sizes and configurations compared to the remainder spines of the tubule. In hydrozoan (Östman, 1983, 1988) and actiniarian microbasic b-mastigophores, the shaft armature consists of large, up to $3-4 \mu \mathrm{m}$ long, closely-set spines generally of the same size (Fig. 2d). In the larger mesobasic b-mastigophores of Metridium senile, the spines of the shaft differ in size (Fig. 2c). The spines on the distal tubule are slender, loosely-set and seldom longer than $1 \mu \mathrm{m}$ (Fig. 2d). 

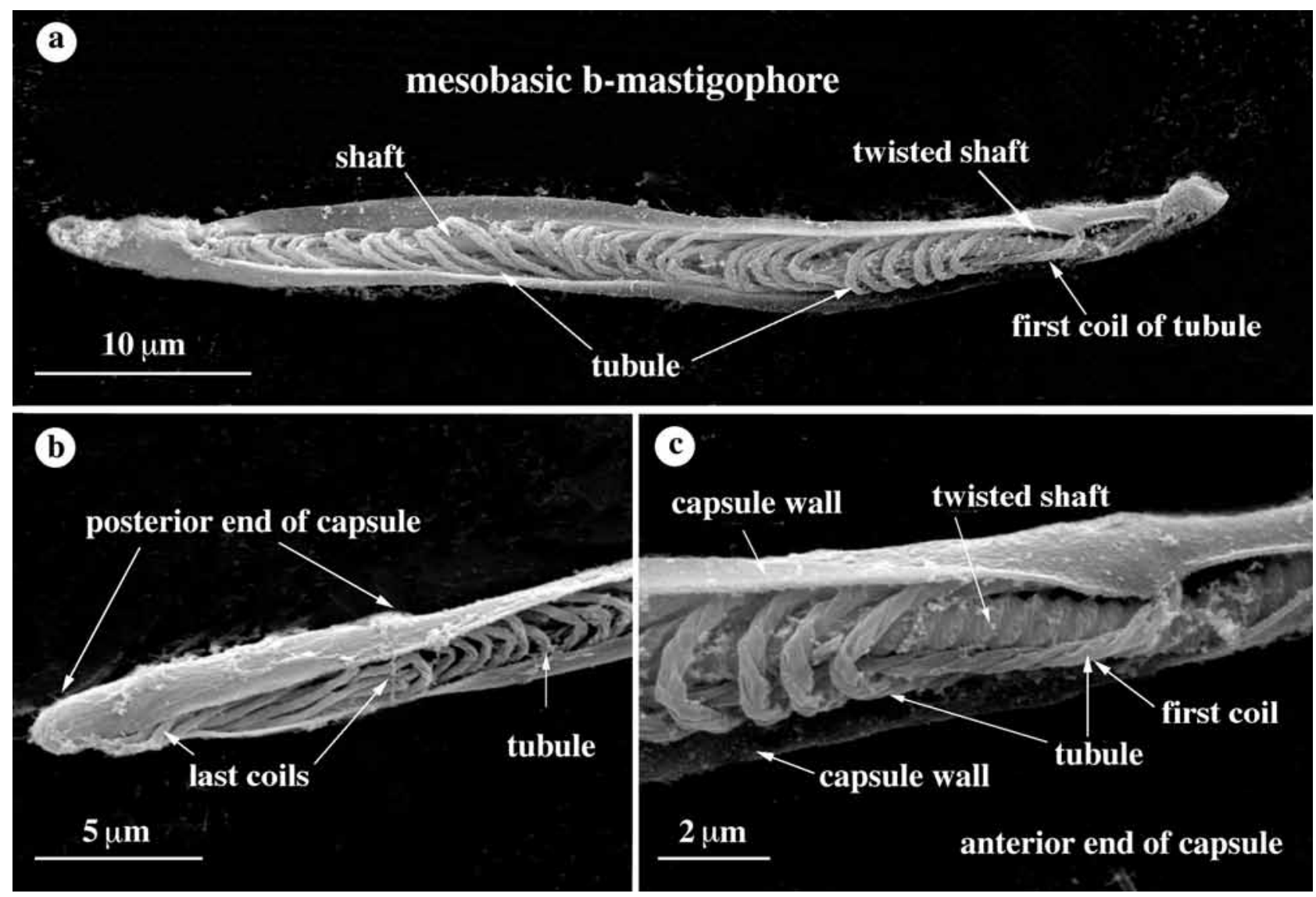

FIG. 6. - SEMs of broken capsules of mesobasic b-mastigophores of Metridium senile showing the twisted shaft and the coiled tubule. a) Note the regular coils of tubule around the shaft. b) Posterior end of a capsule showing the last longitudinal coils of tubule. c) Anterior part of a capsule. Note the twisted shaft and the first coil of the tubule coming from the posterior end of the shaft towards the anterior part of the capsule.

Microbasic and mesobasic amastigophores and microbasic p-amastigophores. Inverted shaft folded back within itself in unfired capsule

The p-mastigophores are by definition (Carlgren, 1940) identified by their inverted shaft, which at its end has a V-shaped notch. Nematocysts with shafts of considerably greater diameter than their distal tubules can be folded within themselves while yet encapsulated. The notch is formed where the broad, encapsulated shaft is folded back within itself (Cutress, 1955; Fig. 2b). First the shaft inverts inward into the capsule, and long shafts can then be folded back inside the shafts again. These shafts are generally broader than shafts without the V-shaped notch, which have no part of shaft folded back within themselves. Since a similar notch is present in amastigophores (Fig. 4c-f) these nematocysts can also be identified by the V-shaped notch at end of unfired shaft.

The remaining narrow, distal tubule of the $\mathrm{p}$ mastigophores is attached at the end of the folded shaft nearest the capsule aperture (Cutress, 1955). Thus part of the inverted distal tubule is within the lumen of the folded shaft. Depending on its length, the remainder of the distal tubule is loosely coiled posteriorly outside the shaft (Fig. 2b).

The amastigophores have, by definition (Carlgren, 1940; Mariscal, 1974), no distal tubule and only a pointed shaft (Figs 4a, 5a,b,c). As in the pmastigophores, inverted shafts of amastigophores are folded back within themselves forming the Vshaped notch at their base (Cutress, 1955). According to Cutress, these nematocysts have a distal tubule at least when undischarged. This short and very thin distal tubule is difficult to see and is easily overlooked (Fig. 4c). As in the pmastigophores, the distal tubule of the amastigophores is attached inside the folded shaft at its end nearest the capsule aperture. The remainder of the distal tubule might be faintly visible. It can be straight or making few irregular coils or loops posterior to the shaft and ending attached to the posterior inner part of the capsule (Fig. 4c). 
Since undischarged amastigophores are equipped with a tubule, Cutress (1955) suggested that the category amastigophores should be eliminated and amastigophores should be merged into the category of p-mastigophores.

Upon discharge, however, the distal tubule of amastigophores seems to break off at or close to the attachment to the shaft (Cutress, 1955), and coils of thin tubule are sometimes visible within the otherwise evacuated capsule (Fig. 5a). The everted cylindrical, broad shaft narrows abruptly to a pointed tip (Fig. 5a-c) or to a tiny, short tubule when parts of the distal tubule are everted along with the shaft (Fig. $4 a$, arrow).

Cutress (1955) also found that some pmastigophores had a shaft divided into one or more darts and classified these nematocysts as qmastigophores, although Hand (1961) and England (1991) regarded the darts as artefacts of spines, which were broken off when shaft everted. Schmidt (1974) noted darts and dart-like structures and regarded them valid. In the present investigation some dart-like structures were observed in SEM preparations of acontia from Metridium senile (Fig. 2e).

\section{Stenoteles, euryteles and birhopaloids}

The inverted shafts of hydrozoan stenoteles are broad, straight and folded back within themselves (Fig. 1d; cf. Tardent, 1988; Östman et al., 1995). The large stylets pointing toward the apex of the capsule and the smaller lamellae or spines of the shaft are readily seen inside the inverted shaft (Fig. 1d). The remaining tubule is irregularly coiled posterior to the shaft (Tardent, 1988) or coiled from wall to wall perpendicularly to the capsule axis in siphonophoran stenoteles (Fig. 1d). When everted, the pointed stylets emerge from the capsule first followed by closely set lamellae or spines (Fig. 1f; Tardent, 1988).

Scyphozoan euryteles (Fig. 3f) and a new type of birhopaloid (type II, Fig. 3e), recently identified in the scyphomedusae Cyanea spp. (see Östman, 1997; Östman and Hyman, 1997), Cotylorhiza tuberculata and Cassiopeia xamachana, have broad and prominent shafts. It has not yet been investigated if the shafts are folded back within themselves. The distal tubules of the euryteles and the birhopaloids make the first loop towards the aperture of the capsule directly after the end of the shaft (Östman and Hyman, 1997).

\section{Systematic value of nematocysts}

Anthozoan species have different cnidomes compared to medusozoan (hydrozoan, schyphozoan and cubozoan) species. Only two categories of cnidocysts, the isorhizas and the microbasic bmastigophores, are present throughout the cnidarian classes (Shostak and Kolluri, 1995). The common actiniarian nematocysts, the p-mastigophores and the amastigophores (Fig. 2), are not present in Scyphozoa. Hydrozoa shares only the p-mastigophores with Siphonophora (Fig. 1e). The large, narrow, elongated nematocyst capsule is also specific for the sea anemones (Fig. 2). These capsules have no lid and three flaps close their aperture. A thickened ridge or flange surrounds the aperture at the junction of the capsule wall with the tubule (Cutress, 1955).

Hydrozoa and Scyphozoa are regarded as more closely related to each other than to Anthozoa and may be merged in the subphylum (or superclass) Medusozoa along with Cubozoa, presumably derived from Scyphozoa. The nematocysts of Hydrozoa and Scyphozoa are also more similar to each other than to those of Anthozoa. The capsules of these medusozoans have a lid, are often broad and rounded to sub-spherical (Fig. 1a,b), and are seldom of the narrow, elongated shape of nematocyst capsules in sea anemones (Fig. 2).

Euryteles, birhopaloids and isorhizas are common nematocysts in hydrozoans as well as in scyphozoans. Microbasic b-mastigophores, which are common in Hydrozoa are, however, only present in cubozoan medusae and not in scyphozoan medusae. The cubozoan are also reported to have the common p-mastigophores of the anthozoans (Rifkin and Endean, 1983). Desmonemes and stenoteles are specific for Hydrozoa (Bouillon, 1985; Tardent, 1988; Östman et al., 1991, 1995). No category of nematocyst is limited specific to Scyphozoa or Cubozoa.

Differences in the cnidomes have taxonomic value at the species level (Gravier-Bonnet, 1987; Östman, 1982, 1988). For more than a century, cnidarian systematists have recorded information on the size and distribution of nematocysts. Carlgren (1940) pointed out that the size of the cnidae is of systematic value and that no description of a species is complete unless it includes annotation on the size of nematocysts. The sizes of cnidocysts are especially valuable for distinguishing those species, which have the same cnidome (Östman, 1979a,b; Östman and Hyman 1997). 
Nematocysts also differ in size within the animal (Carlgren 1940, 1945; Schmidt 1974; Östman and Hyman, 1997) and some are large in animals of larger size (Östman and Hyman, 1997). The sizes of nematocysts differ in specific organs and parts of organs. The same nematocyst type can appear in several different size classes present in the same organ or in different organs of the same animal. The bmastigophores within Metridium senile, for example, can differ by up to $50 \mu \mathrm{m}$ (Fig. 2a). Furthermore, young animals frequently possess categories of nematocysts that are absent in older animals (Kubota, 1978a,b; Östman et al., 1995) and animals in different stages of metagenesis (their life-cycle) have different cnidomes. This is the case, for example, in planulae, scyphistomae and medusae of Scyphozoa (Calder, 1971, 1972, 1974, 1977, 1983; Östman, 1997; Östman and Hyman, 1997), the actinulae and polyps of Tubularia larynx (see Östman et al., 1995), and for the colony and medusa of Clytia hemispherica (see Östman, 1979a,b). To be of value for taxonomic diagnosis, therefore, measurements must be taken from all the major types of nematocysts present in a species throughout its life cycle, and in different organs and parts of the same animal.

\section{DISCUSSION}

The criteria for identifying different nematocyst types proposed by Weill (1934) have been enormously influential on cnidarian scientists; although the nomenclature for basic nematocyst categories has altered, new categories have been added (Carlgren, 1940; Cutress, 1955, Bouillon et al., 1986), and other modifications have been made (Carlgren, 1940; Cutress, 1955; Mariscal, 1974; Calder, 1974; Östman, 1988; Östman and Hyman, 1997). Due to the improvement of the light microscope and the advent of SEM, some additional modifications ought to be made. This is most simply accomplished by retaining as far as possible the descriptive nomenclature of basic categories while adjusting definitions to suit new data.

\section{Proposed changes in definitions of extant nema- tocyst nomenclature}

\section{Isorhizas and anisorhizas}

Small spines, of only a few micrometers in length, were not observed by Weill (1934) and earlier nematocyst workers. Atrichs and basitrichs of
Weill have later been found to be spined throughout the length of their tubules (Cutress, 1955; Westfall, 1966a,b; Calder, 1974; Heeger et al., 1992; Östman, 1983). Calder (1974) suggested changing Weill's terminology of the a-atrichs and A-atrichs to aisorhizas and A-isorhizas. Some isorhizas, however, are spineless and can thus be regarded as atrichous isorhizas (Östman, 1982). Moreover, during part of their development, some isorhizas are spineless.

The definition of basitrich as "nematocysts with a tube of uniform diameter, which bears coarse armature proximally for a distance less than three times the capsule length' is valid for the basal spines of some isorhizas and anisorhizas (see Cutress, 1955). Some isorhizas within the family Campanulariidae (Östman, 1982) and basitrichs of sea anemones (Cutress, 1955) can be referred to as basitrichous isorhizas.

The distinction between the anisorhizas and isorhizas is not clear, however (see Cutress, 1955; England, 1991; Östman et al., 1995; Östman and Hyman, 1997 for thorough discussion). Rather than being of uniform diameter throughout, the tubules of isorhizas may gradually become more slender towards the distal end. Isorhizas, therefore, are better defined as nematocysts whose tubule proximal to the mid-region is of constant or nearly constant diameter (Östman and Hyman, 1997).

\section{Microbasic and mesobasic b-mastigophores}

A distinct shaft is not present in all discharged bmastigophores in species of hydrozoans (Östman, 1983, 1987) and in sea anemones (Fig. 2d), contrary to the assertions of Carlgren (1940) and Mariscal (1974). The difference in diameter of proximal and distal tubule of b-mastigophores is often very small or non-existent (Cutress, 1955; Östman, 1979a,b, 1987, 1988). Cutress (1955) remarked that the difference between the diameter of the everted 'shaft' and of the distal tubule of b-mastigophores could be as small as $0.1 \mu \mathrm{m}$. The proximal armature, however, is prominent and clearly visible in LM (Fig. 2c) compared to the unspined or loosely spined remaining tubule (Fig. 2d).

Differences in the relative diameters of the proximal and distal tubule cannot always be ascertained in the LM when a proximal tubule is armed with closely set spines. Thus, most discharged bmastigophores can only be identified by their proximal armature, although in undischarged bmastigophores, the proximal tubule is distinguished 
from the remaining distal tubule by a straight, rodshaped structure (Fig. 2a). The diagnostic criteria for the b-mastigophores should include, in addition, differences between the prominent proximal armature and smaller spines on the distal tubule or the spineless tubule (Fig. 2d).

The distinction between the basitrichs and the bmastigophores made by England (1991) is also blurred following eversion. The basitrichs are more readily distinguished from the b-mastigophores when undischarged (cf. Cutress, 1955). The tubule of basitrichs is completely coiled proximally (Cutress, 1955), whereas that of b-mastigophores is uncoiled basally, forming the rod-shaped proximal tubule. The distinction between b-mastigophores and basitrichs is further obscured, because the first coil of some basitrichs is large enough to resemble the rod-shaped proximal tubules of bmastigophores, whereas some thin, short-shafted bmastigophores coil much like the tubules of basitrichs (cf. Cutress, 1955).

\section{Microbasic p-mastigophores and micro- and mesobasic p-amastigophores}

The shaft in undischarged amastigophores has a V-shaped notch resembling that of an unfired pmastigophores (Carlgren, 1940) (Fig. 2b, 4c). The broad, invaginated shaft forms the V-shaped pattern when it is folded back within itself (Cutress, 1955). Contrary to Cutress (1955), who merged the amastigophores into the p-mastigophores, the amastigophores are recognised in the present work as a valid category, even while acknowledging that a tiny tubule is visible in the undischarged capsule (Fig. 4c). The prefix 'p' is thus added before 'amastigophore' to indicate the similarity in the structure of the shaft with the p-mastigophores. The category amastigophore is thus changed to $\mathrm{p}$ amastigophore. Undischarged p-mastigophores and p-amastigophores are difficult to separate in sea anemones, since the tubules of some of the pmastigophores are mostly invisible, but, following discharge, p-amastigophores are readily distinguished from the p-mastigophores due to the absence of a tubule beyond the shaft (Fig. 4a).

\section{Microbasic and mesobasic}

England (1991) proposed the term mesobasic for shafts that had a tightly twisted part corresponding to the folded portion described by Schmidt (1969,
1972, 1974). Following discharge, the mesobasic shaft was less than four times the capsule length.

Defining the degree of shaft folding in small and medium-sized nematocysts can be problematic, but 'mesobasic' is easily defined exclusively to terms of shaft length. Accordingly, mesobasics are redefined as nematocysts whose shafts are slightly longer than one and a half time but less than four times the capsule length. Shafts longer than one and a half time the capsule length when discharged are generally more tightly twisted proximally (corresponding to the folded portion of Schmidt, 1969) and slightly undulating or coiled when undischarged (Fig. 4e,f). Undischarged microbasic shafts can often be distinguished from mesobasic shafts by their rod-shaped straight, short shaft (Fig. 4c,d).

\section{Nematocyst nomenclature and classification}

Stephenson (1929) began the modern effort to systematise nematocyst nomenclature. He placed pmastigophore and amastigophore nematocysts together and named them 'penicilli'. The basitrichs and some microbasic b-mastigophores were given the name 'spirule'.

Weill's (1934) nomenclature was, however, generally accepted by cnidarianists, and considerable effort was spent bringing cnidocysts described in the old literature into Weill's scheme (Shostak and Kolluri, 1995) even if it did not solve all the problems of classification. Weill (1934) had subdivided the nematocysts into two main groups: the stomocnidae (nematocyst with tubule open at tip) and astomocnidae (nematocysts with tubule closed at tip). The majority of penetrating nematocysts were assigned to the stomocnidae. Generally nematocysts whose tubules entangle prey were assigned to the astomocnidae (Weill, 1934; Mariscal, 1974).

Werner (1965) doubted the reliability of observations on tubule tips, and Rifkin (1996) stated that some penetrating nematocysts assigned to the stomocnidae had closed tips when fully discharged, while droplets of capsular matrix ruptured tubules. The tip of discharged p-amastigophores of sea anemones examined in the present study seemed also to be closed (Fig. 5a,c). Furthermore, the large A-isorhizas of Cyanea spp. entangle prey and were apparently not penetrators (Östman and Hyman, 1997), although isorhizas were assigned to the stomocnidae. Thus, if the categories of astomocnidae and stomocnidae were to be retained for identifying nematocysts, their definitions would require modification (see below). 
Schmidt (1969, 1972, 1974) also introduced a rational nomenclature, but it caused confusion by using synonyms for nematocysts already well known in other nomenclatures. For example the brhabdoids of Schmidt are virtually the same as the microbasic b-mastigophores of Weill (Östman, 1987). The pseudo-microbasic b-mastigophores (Östman, 1989) can also be merged with microbasic b-mastigophores. The polyspiras of Spangenberg (1965) are certainly one type of isorhiza (Östman and Hyman, 1997).

Cnidocyst nomenclature would seem best served by modifying the definitions of widely used terms in accordance with descriptions from modern LM and SEM of the everted tubule with its pattern of spines as well as the form of tubule-coiling within the unfired capsules. The classification system of Mariscal (1974) based on the nomenclature of Weill (1934) is most easily changed to accommodate these modification.

The desmonemes are the only astomocnidae examined by the author (Östman et al. 1991, 1995). The main concern of this work is thus the nomenclature of nematocysts assigned to the stomocnidae, which have been examined by the author during previous and the present study.

\section{Modified classification based on Mariscal (1974)}

I. ASTOMOCNIDAE: Tubule closed at tip; generally entangles prey.

Desmonemes: tubule forms a corkscrew-like coil. Few coils of tubule visible in undischarged capsule.

II. STOMOCNIDAE: Most tubules open at tip; mainly penetrants.

A. HAPLONEMES: no prominent, rod-shaped shaft visible inside undischarged capsule.

1. Isorhizas: tubule isodiametric or nearly isodiametric proximal to the mid-point and tapering thereafter.

a. Atrichous or holotrichous: tubule unspined or armed with tiny spines throughout.

b. Basitrichous: prominent large spines close to capsule. Remaining tubule unspined or armed with tiny spines.

2. Anisorhizas: tubule slightly dilated towards base.

a. Atrichous or holotrichous: tubule unspined or armed with tiny spines throughout.

b. Basitrichous: prominent large spines close to capsule. Remaining tubule unspined or armed with tiny spines.

B. HETERONEMES: prominent shaft visible inside undischarged capsule.

B1. Microbasic: discharged shaft or proximal tubule with prominent armature short, less than one and a half times capsule length.

B2. Mesobasic: discharged shaft or proximal tubule with prominent armature medium-sized, more than one and a half times longer but shorter than four times capsule length.

B3. Macrobasic: discharged shaft or proximal tubule with proximal armature long, more than four times the capsule length

1. Rhabdoids: inverted shaft rod-shaped, everted tubule with prominent spines generally of the same size.

a. Mastigophores: tubule continues beyond shaft or proximal armature.

(a) p-mastigophores: V-shaped notch at base of unfired, broad shaft; discharged shaft tapers abruptly into tubule.

(b) b-mastigophores: No V-shaped notch at base of unfired, narrow shaft; discharged shaft or proximal tubule approximately the same diameter as remaining tubule.

b. Amastigophores: no tubule beyond everted shaft;

(a) p-amastigophores: V-shaped notch at base of unfired shaft (changed terminology.

2. Rhopaloids: shaft of unequal diameter a. Euryteles: discharged shaft dilated distally.

(a) Homotrichous: spines of shaft all of the same size.

(b) Heterotrichous: spines of shaft of unequal size.

b. Stenoteles: discharged shaft dilated at base, large spines at point of constriction between basal and distal part.

(a) Stenoteles proper: three stylets or especially strong spines at constriction, distal portion armed by rows of lamellae or spines.

(b) Pseudostenoteles: two to four large spines at constriction, distal portion of shaft long, armed with smaller spines; sometimes also with a few large ones (new category, Boullion et al., 1986).

c. Birhopaloids: discharged shaft with one distal and one proximal dilatations.

(a) Birhopaloides type I. The two dilations separated from each other.

(b) Birophaloides type II. The two dilations 
close together (new category or similar to trirophaloids of Rifkin (1996)).

III. Spirocysts: thin capsule wall, containing a long spirally coiled tubule of uniform diameter (Fig. 4d). No shaft or spines distinguishable.

\section{ACKNOWLEDGEMENTS}

Dr. Stanely Shostak is acknowledged for transforming my manuscript to good English and to a more professional style. Much of the investigations were carried out at Klubban Biological Station, University of Uppsala, and at the Marine Research Station, The Royal Swedish Academy of Science, both in Fiskebäckskil on the west coast of Sweden. I thank the directors and the staffs for their hospitality and for providing facilities. The SEM and the computer work were performed in Uppsala at the Evolutionary Biology Centre, Uppsala University. Financial report was obtained from the Faculty of Science at Uppsala University and from O. E. and Edla Johanssons Scientific Foundation, Myrberg and Partner, Kapitalförvaltning AB, Stockholm.

\section{REFERENCES}

Arai, M. N. - 1997. A functional biology of Scyphozoa. Chapman and Hall, London.

Bedot, M. - 1896. Note sur les cellules urticantes. Revue Suisse Zool., 3: 533-539.

Bouillon, J. - 1985. Essai de classification des Hydropolypes Hydroméduses (Hydrozoa - Cnidaria). Indo-Malayan Zool., 1: $29-243$

Bouillon, J., F. Boero and N. Gravier-Bonnet. - 1986. Pseudostenoteles, a new type of nematocyst, and its phylogenetic meaning within Haleciidae (Cnidaria, Hydrozoa). IndoMalayan Zool., 3: 63-69.

Calder, D.R. - 1971. Nematocysts of polyps of Aurelia, Chrysaora, and Cyanea, and their utility in identification. Trans. Amer. Microscop. Soc., 90: 269-274.

Calder, D.R. - 1972. Nematocysts of the medusa stage of Rhopilema verrilli (Scyphozoa, Rhizostomeae). Trans. Amer. Microscop. Soc., 91: 213-216.

Calder, D.R. - 1974. Nematocysts of the coronate scyphomedusa, Linuche unguiculata, with a brief re-examination of scyphozoan nematocyst classification. Chesapeake Sci., 15: 170-173.

Calder, D.R. - 1977. Nematocysts of the ephyra stages of Aurelia, Chrysaora, Cyanea, and Rhopilema (Cnidaria, Scyphozoa). Trans. Amer. Microscop. Soc., 96: 13-19.

Calder, D.R. - 1983. Nematocysts of stages in the life cycle of Stomolophus meleagris, with keys to scyphistomae and ephyrae of some western Atlantic Scyphozoa. Canadian J. Zool., 61: $1185-1192$

Carlgren, O. - 1940. A contribution to the knowledge of the structure and distribution of the cnidae in Anthozoa. Lunds Univ.'s Årskrift, 36: 1-62.

Carlgren, O. - 1945. Further contributions to the knowledge of the cnidom in the Anthozoa especially in the Actiniaria. Lunds Univ.'s Årskrift, 41(9): 1-24.

Cutress, C.E. - 1955. An interpretation of the structure and distribution of Cnidae in Anthozoa. Syst. Zool., 4: 120-137.

Den Hartog, J.C. - 1977. The marginal tentacles of Rhodactis sanc- tithomae (Corallimorpharia) and the sweeper tentacles of Montastrea cavernosa (Scleractinia); their cnidom and possible function. In: Proceedings, Third International Coral Reef Symposium. Rosenstiel School of Marine and Atmosphaeric Science. pp. 463-470. Miami, Univ. Miami.

Den Hartog, J.C. - 1980. Caribbean shallow water Corallimorpharia. Zool. Verh., 176: 1-83.

England, K.W. - 1991. Nematocysts of sea anemones (Actiniaria, Ceriantharia and Coralliomorpharia). Hydrobiologia, 216/217: 691-697.

England, K.W. - Chapter 3. Nematocysts. Upublished manuscript.

Gravier-Bonnet, N. - 1987. Nematocysts as taxonomic discriminators in thecate hydroids. In: J. Bouillon, F. Boero, F. Cigogna and P.F.S. Cornelius (eds.): Modern Trends in the Systematics, Ecology and Evolution of Hydroids and Hydromedusae. pp. 4355. Clarendon Press, Oxford.

Hand, C. - 1961. Present state of nematocyst research: Types, structure and function. In: H.M. Lenhoff, and W.F. Loomis (eds.): The Biology of Hydra. pp. 187-202. Univ. Miami Press, Coral Gables, Florida.

Heeger, T., H. Müller and U. Mrowietz. - 1992. Protection of human skin against jellyfish (Cyanea capillata) stings. Mar. Biol., 113: 669-678.

Itô, T. and K Inoe. - 1962. Systematic studies on the nematocysts of Cnidaria 1. Nematocysts of Gymnoblastea and Calyptoblastea. Mem. Ehime Univ., II (Sci) 4: 445-460.

Kubota, S. - 1976. Notes on the nematocysts of Japanese hydroids, I. J. Fac. Sci. Hokkaido Univ. Ser. 6, Zool., 20: 230-243.

Kubota, S - 1978a. The life-history of Clytia edwardsi (Hydrozoa, Campanulariidae) in Hokkaido, Japan. J. Fac. Sci. Hokkaido. Univ. Ser., (VI-Zool.) 21: 317-354.

Kubota, S - 1978b. Notes on Clytia and Phialidium (Hydrozoa, Campanulariidae) from Shimoda, Japan. Proc. Jap. Soc. Syst. Zool., 15: 1-7.

Mariscal, R.N. - 1974. Nematocysts. In: L. Muscatine and H. M. Lenhoff (eds.), Coelenterate Biology, pp. 129-178. Academic Press, New York.

Mariscal, R.N., E.J. Conklin and C.H. Bigger. - 1977. The ptychocyst, a major new category of cnidae used in the tube construction by cerianthid anemone. Biol. Bull., 152: 392-405.

Östman, C. - 1979a. Two types of nematocysts in Campanulariidae (Cnidaria, Hydrozoa) studied by light and scanning electron microscopy. Zool. Scripta, 8: 5-12.

Östman, C. $-1979 \mathrm{~b}$. Nematocysts in the Phialidium medusae of Clytia hemisphaerica (Hydrozoa, Campanulariidae). Zoon, Uppsala, 7: 125-142.

Östman, C. - 1982. Nematocysts and taxonomy in Laomedea, Gonothyraea and Obelia (Hydrozoa, Campanulariidae). Zool. Scripta, 8: 5-12.

Östman, C. - 1983. Taxonomy of Scandinavian hydroids (Cnidaria, Campanulariidae): A study based on nematocyst morphology and isoenzymes. Acta Univ. upsaliensis, 672: 1-22.

Östman, C. - 1987. New techniques and old problems in hydrozoan systematics. In: J. Bouillon, F. Boero, F. Cigogna and P. F. S. Cornelius (eds.), Modern Trends in the Systematics, Ecology and Evolution of Hydroids and Hydromedusae. pp. 67-82. Clarendon Press, Oxford.

Östman, C. - 1988. Nematocysts as taxonomic criteria within the family Campanulariidae, Hydrozoa. In: D. A. Hessinger and H. M. Lenhoff (eds.), The Biology of Nematocysts. pp. 501-517. Academic Press, San Diego.

Östman, C. - 1991. Scanning electron microscopic observations on Scandinavian scyphozoans with special references to their nematocysts. In: Proceedings of the II Workshop on Jellyfish in the Mediterranean Sea, Map Technical Rep. Ser., 47: 283-292.

Östman, C. - 1997. Abundance, feeding behaviour and nematocysts of scyphopolyps (Cnidaria) and nematocysts in their predator; the nudibranch Coryphella verrucsa (Mollusca). In: A. D. Naumov, H. Hummel, A. A. Sukhotin and R. Ryland (eds), Interactions and Adaption Strategies of Marine Organisms. Hydrobiologia, 355: 21-28.

Östman, C. - 1999. Nematocysts and their value as taxonomic parameters within the Campanulariidae (Hydrozoa). A review based on light and scanning electron microscopy. In: S. D. Stepanjants (ed), Obelia (Cnidaria, Hydrozoa). Phenomenon. Aspects of investigations. Perspectives of employment. Zoosyst. Rossica. Suppl. No.1: 17-28.

Östman, C., W.R. Kem and S. Pirano. - 1991. Nematocysts of the 
Mediterranean hydroid Halocordyle disticha (Goldfuss 1820). Hydrobiologia, 216/217: 607-613.

Östman, C., A. Aquirre, M. Myrdal, P. Nyvall, J. Lindström and M. Björklund. - 1995. Nematocysts in Tubularia larynx (Cnidaria, Hydrozoa) from Scandinavia and the northern coast of Spain. Sci. Mar., 59(2): 165-179

Östman, C. and J. Hyman. - 1997. Nematocyst analysis of Cyanea capillata and Cyanea lamarckii (Scyphozoa, Cnidaria). Sci. Mar., 61(3): 313-344.

Rifkin, J. - 1996. Cnida structure and function. In: J.A. Williamson, P.J. Fenner, J.W. Burnett, J.F. Rikin (eds), Venomous Marine Animals: A Medical and Biological Handbook, pp. 155-173. University of New South Wales Press, Sydney.

Rifkin, J. and R. Endean. - 1983. The structure and function of the nematocysts of Chironex fleckeri Southcott, 1956. Cell Tissue Res., 233: 563-577.

Schmidt, H - 1969. Die nesselkapslen der Aktinien und irhe differentialdiagnostische Bedeutung. Helgoländer wiss. Meeresunters., 19: 284-317.

Schmidt, H. - 1972. Die Nesselkapseln der Anthozoen und ihre Bedeutung fur die phylogenetische Systematik. Helgoländer wiss. Meeresunters., 23: 422-458.

Schmidt, H. - 1974. On evolution in the Anthozoa. Proceedings 2nd international Coral Reef Symposium, Great Barrier Reef Commitee, Brisbane, pp. 533-560.

Shostak, S. and W. Kolluri. - 1995. Symbiogenetic origins of Cnidarian cnidocysts. Symbiosis, 19: 1-29.
Slautterback, D.B. and D.W. Fawcett. - 1959. The development of the cnidoblasts of Hydra: an electron microscope study of cell differentiation. J. Biophys. Biochem. Cytol., 5: 441-451.

Stephenson, T.A. -1929 . On the nematocysts of sea anemones. $J$. Mar. Biol. Ass. U. K., 16: 173-200.

Spangenberg, D.B. - 1965. A study of strobilation in Aurelia under controlled condition. J. Exp. Zool., 160: 1-9.

Tardent, P. - 1988. History and current state of knowledge concerning discharge of Cnidae. In: D.A. Hessinger and H.M. Lenhoff (eds.), The Biology of Nematocysts. pp. 309-332. Academic Press, San Diego.

Watson, G.M. and R.L. Wood. - 1988. Colloquium on Terminology. In: D.A. Hessinger and H.M. Lenhoff (eds.), The Biology of Nematocysts. pp. 21-23. Academic Press, San Diego.

Weill, R. - 1934. Contribution à l' étude des cnidaires et de leurs nématocystes. I, II. Trav. Stn. zool. Wimereux, 10 and 11: 1701.

Werner, B. - 1965. Die Nesselkapseln der Cnidaria, mit besonderer Berucksichtigung der Hydroida. I. Klassifikation und Bedeutung fur die Systematik and Evolution. Helgoländer wiss. Meeresunters., 12: 1-39.

Westfall, J.A. - 1966a. The differentiation of nematocysts and associated structures in the Cnidaria. Z. Zellforsch. microsk. Anat., 75: 381-403.

Westfall, J.A. - 1966b. Electron microscopy of the basitrich and associated structures in Obelia. Am. Zool., 6: 554. 